\title{
ECOLOGIA POLÍTICA, JUSTIÇA E EDUCAÇÃO AMBIENTAL CRÍTICA: PERSPECTIVAS DE ALIANÇA CONTRA-HEGEMÔNICA
}

\author{
POLITICAL ECOLOGY, JUSTICE, AND CRITICAL ENVIRONMENTAL EDUCATION: PERSPECTIVES OF A \\ COUNTER-HEGEMONIC ALLIANCE
}

\author{
Carlos Frederico B. Loureiro ${ }^{1}$ \\ Philippe Pomier Layrargues ${ }^{2}$
}

Resumo Objetivamos com o presente artigo trazer alguns argumentos e contribuições teóricas que sustentam a pertinência da articulação entre a denominada educação ambiental crítica e o movimento de justiça ambiental, em decorrência da aproximação no modo como definem as causas da crise atual, estabelecem estratégias de luta social e defendem o projeto societário anticapitalista. Essa articulação não só é oportuna para os processos de superação das relações sociais alienadas destrutivas da natureza, mas também reforça uma perspectiva da ecologia política, para a qual as determinações são materiais e de classe. Nos três movimentos - educação ambiental crítica, justiça ambiental e ecologia política - ocorre um processo argumentativo contínuo de ressignificação ideológica da questão ambiental, agindo como contraponto das interpretações hegemônicas do senso comum acerca do fenômeno socioambiental. Todos possuem elementos em comum que conformam o amálgama mediante o qual se pode efetuar a crítica e operar politicamente a favor da transformação social.

Palavras-chave ecologia política; movimentos sociais; justiça ambiental; educação ambiental crítica; ambientalismo.
Abstract The purpose of this article is to raise a few arguments and make theoretical contributions to support the pertinence of the link between the so-called critical environmental education and the environmental justice movement due to the approach in how they define the causes of the current crisis, establish social struggle strategies, and defend the anti-capitalistic corporate project. This link is not only timely for the process of overcoming the destructive, alienated social relations of nature, but also underpins a perspective of the political ecology for which the determinations are material and of class. In the three movements - critical environmental education, environmental justice and political ecology - there is an ongoing argumentative process of ideological resignification of the environmental issue, acting as a counterpoint for the hegemonic interpretations of the common sense on the socioenvironmental phenomenon. They all have elements in common that form the amalgamation through which one can critique and, yet, operate politically on behalf of social transformation. Keywords political ecology; social movements; environmental justice; critical environmental education; environmentalism. 


\section{Introdução}

O processo de institucionalização da produção acadêmica e da consolidação da educação ambiental como campo social no Estado brasileiro intensificouse consideravelmente na última década. Esse processo é reflexo de um movimento histórico de cerca de quatro décadas, promovido por agentes sociais vinculados aos mais diferentes setores da sociedade, portadores de discursos ancorados em práticas distintas, por vezes antagônicas, que expressam o modo como compreendem, produzem e apreendem a 'questão ambiental' e atuam no enfrentamento dos problemas contemporâneos por meio da educação (Lima, 2011).

A aceitação por parte dos sujeitos envolvidos de que um campo social não é homogêneo ou derivado de finalidade comum, abstratamente posta na sociedade como algo consensual, expressa o próprio movimento de amadurecimento do mesmo e não sua fragilização (Layrargues, 2010). Do ponto de vista teórico e epistemológico, uma maior clareza e explicitação das maneiras como o conhecimento, os discursos e as práticas sociais se produzem são indicativos de quais projetos societários em disputa, em suas dinâmicas e relações contraditórias, estão se objetivando no plano social, permitindo entender as conformações do próprio campo social (Bourdieu, 2005 e 2007).

Dessa forma, concordamos com a sintética e precisa definição de campo social exposta por Lima:

O universo social onde pessoas, grupos e instituições que dele participam se definem pelas relações de concorrência e poder que estabelecem entre si, visando à hegemonia simbólica e material sobre esse universo de atividade e de saber. Compreende um conjunto de relações de força, de interesse, de conflito onde se estabelecem alianças, estratégias e investimentos que visam à conquista do objeto em disputa no campo, no caso, o capital simbólico legitimado, fundado sobre atos de conhecimento e de reconhecimento pelo conjunto dos pares concorrentes no interior do campo social. Como qualquer jogo, o campo social possui estrutura própria, dotada de posições determinadas pela distribuição de capital ou de poder específico do campo, objetivos, normas e valores particulares que o orientam. Por ser um espaço concorrencial, o campo pressupõe relações internas assimétricas derivadas da desigual distribuição de poder entre grupos dominantes e dominados. Os dominantes são os que definem o capital social legítimo do campo - objeto de disputa entre seus participantes - e, portanto, as regras do jogo, tendem à ortodoxia e desenvolvem estratégias de conservação; enquanto os dominados tendem à heterodoxia e ao uso de estratégias de subversão da ordem (Lima, 2005, p. 16).

Isso posto, longe de defendermos uma educação ambiental única em seu entendimento de mundo e forma de agir, partimos do pressuposto de que 
sua natureza conflitiva, na diversidade e na disputa de concepções e espaços na sociedade, fortalece-a e a legitima nas institucionalidades acadêmicas, nas políticas públicas e nos movimentos sociais que buscam a garantia de direitos, a afirmação das diferenças, a superação das desigualdades de classe e a construção de outro patamar societário.

No presente artigo, e considerando esse contexto, objetivamos trazer algumas contribuições teóricas e argumentos que sustentam a pertinência da articulação entre a denominada educação ambiental crítica e o movimento de justiça ambiental, em decorrência da aproximação no modo como definem as causas da crise atual, estabelecem estratégias de luta social e defendem o projeto societário anticapitalista (Acselrad, Mello e Bezerra, 2008; Rios, 2011).

Essa articulação e diálogo, em nosso entender, não apenas são oportunos para os processos de superação das relações sociais alienadas destrutivas da natureza (Alier, 2007; Altvater, 2010; Mészáros, 1989), como também reforçam uma perspectiva da ecologia política para a qual as determinações são materiais e de classe.

Esse deslocamento, muito mais do que uma virada teórica, implica mudanças práticas e políticas. Argumentamos, em síntese, que a incorporação teórica das diferenças (Mouffe, 2001) e do reconhecimento (Honnet, 2003) como constitutivos da condição humana e dos dilemas contemporâneos complexifica as lutas sociais e as práticas cotidianas, mas não altera a especificidade ontológica do ser social, fundada na atividade práxica, primordialmente o trabalho, e nas determinações materiais historicamente estabelecidas (Lukács, 2010).

Assim, para o cumprimento desse objetivo, partimos de breve histórico e caracterização da ecologia política e suas disputas internas no tratamento da crise ambiental. Em seguida, discorremos sobre a polêmica relação entre os movimentos sociais e a temática ambiental, comentando alguns aspectos do movimento de justiça ambiental que permitem relacionar suas lutas à educação ambiental. Por fim, indicamos pontos centrais da educação ambiental sob um olhar crítico, buscando evidenciar as articulações possíveis e, no nosso entender, necessárias para o enfrentamento organizado da intensificação do processo de expropriação material e acumulação de capital que se universaliza e coloca sob profunda ameaça a reprodução da vida, dentre elas a humana, na Terra.

\section{Ecologia política}

A ecologia política tem sua origem nos anos 1960, e se refere, como objeto de estudo, à compreensão de que agentes sociais com diferentes e desiguais 
níveis de poder e interesses diversos demandam, na produção de suas existências, recursos naturais em um contexto ecológico, disputando-os e compartilhando-os. O seu objetivo, com isso, é gerar conhecimentos e a compreensão do próprio modo de funcionamento societário enquanto exigência para a intervenção política superadora ou reprodutora das condições estruturais que engendram modos específicos de produção e relações de propriedade dos bens criados ou naturais. A ecologia política, em resumo, focaliza a atenção nos modos pelos quais agentes sociais, nos processos econômicos, culturais e político-institucionais, disputam e compartilham recursos naturais e ambientais e em qual contexto ecológico tais relações se estabelecem.

O diferencial da ecologia política em relação à economia política, portanto, não está na aceitação da natureza como condição para a produção, pois isso é inerente a qualquer análise econômica, mas no modo como ela é qualificada. Na ecologia política a natureza é vista não somente como fonte de recursos, mas como ontologicamente prioritária para a existência humana, aquilo que nos antecede e que de nós independe, cuja dinâmica ecológica, mesmo que por nós mediada e transformada, precisa ser conhecida e respeitada a fim de que o modo de produção seja compatível com sua capacidade de suporte e de regeneração (Foladori, 2001).

Não seria exagero dizer que a ecologia política teve a capacidade de explicitar a grande contradição da contemporaneidade, cujo sistema sustenta um adequado padrão de vida para alguns em detrimento do péssimo padrão de vida para outros, e com base no uso abusivo e intensivo da natureza. E isso não apenas é materialmente insuportável, como também é eticamente abominável, exigindo, portanto, a superação da sociedade de classes e dos costumes e valores morais nela legitimados (Gorz, 1976).

Todavia, essa posição da ecologia política que se expressa no debate dos movimentos sociais de teor classista, no movimento de justiça ambiental e na abordagem crítica da educação ambiental, perde centralidade explicativa do real, cedendo espaço para outra abordagem que cresceu significativamente nos últimos vinte anos, por força das próprias discussões postas pelos pós-modernos e pós-estruturalistas, e diante da denominada crise do socialismo real. Com essa outra abordagem, configura-se uma perspectiva culturalista para o tratamento do que é ambiental voltada para o entendimento dos significados, da afirmação da diversidade cultural e da aceitação dos discursos como sinônimo de possibilidade de verdade, subsumindo a objetividade na subjetividade (Alier, 2007).

Uma posição, a crítica, com forte inspiração marxista em suas múltiplas 'escolas', define os processos linguísticos, simbólicos e de comunicação como dialeticamente vinculados à prática social, à economia e à produção de meios de vida e de satisfação de necessidades. Com isso, sociabilidade, re- 
conhecimento, linguagem e trabalho formam uma unidade composta de momentos distintos e mutuamente determinados, tendo no trabalho o ato fundante do ser social, posto que esse é o metabolismo entre o ser humano e a natureza, objetivando o humanamente subjetivo e subjetivando o humanamente produzido. Ou seja, cada dimensão só se define como tal em relações que manifestam a contraditoriedade do real (Loureiro, 2007). Logo, o discurso, por exemplo, é material, pois só existe com base em práticas sociais que estabelecem as condições objetivas de nossa atividade, tanto sendo produzida na materialidade das relações quanto sendo produtora da mesma.

A outra posição, bastante diversa e composta de um amplo leque de opções teóricas, com formulações que podem ser de inspiração de pragmáticos críticos, como Habermas ou Boaventura de Sousa Santos, até relativistas pós-modernos, como Deleuze, parte, como ponto mais comum (desconsiderando as profundas divergências), de uma compreensão dual da realidade. Portanto, aqui é possível pensar a linguagem e a comunicação como processo autônomo da atividade práxica e do trabalho, ou mesmo a necessidade de reconhecimento do outro como uma exigência ética e genética não determinada pelas relações reificadas do modo de produção capitalista.

Sem entrar em maiores detalhes acerca desse extenso debate, discorremos um pouco mais com argumentos que sustentam, em razão do objetivo do texto, a pertinência da primeira posição (a crítica) para o momento presente da crise ambiental.

Nos últimos trinta anos, houve um movimento de liberalização da economia, de flexibilização do trabalho e de reorganização do Estado para garantir a continuidade do modelo de expansão e acumulação do capital, que se reflete na possibilidade de o ambiente servir a interesses públicos em uma sociedade marcada pelo poder do interesse privado. As ações envolvem, entre outras medidas, redução dos gastos públicos, abertura das economias ao capital estrangeiro e privatização das empresas e serviços públicos.

Nesse movimento das relações econômicas e da organização do Estado, há toda uma argumentação ideologicamente construída que afirma termos chegado ao fim das ideologias, da centralidade do trabalho, das classes sociais, dos conflitos e da importância do Estado na promoção de políticas sociais. Apresenta-se, para tanto, a justificativa de que, com o avanço dos serviços, do empreendedorismo, da tecnologia e da ciência, a relação assalariada perdeu espaço, e as formas de organização dos trabalhadores entraram em colapso. Confunde-se assim trabalho com emprego e 'esquece-se' que os mecanismos criados não geraram trabalho livre e sim maior subordinação aos movimentos de reprodução e valorização do capital. Pensa-se a ciência como libertação, desprezando-se que ela é feita por trabalhadores e instituições inseridas na produção (Organista, 2006). Fala-se também em imaterialidade da sociedade, mas jamais se demandou tanta matéria e 
produção de mercadorias para garantir um modo de vida pautado no consumismo e na obsolescência e descartabilidade das mercadorias (Alier, 2007). Apresenta-se o setor de serviços como menos impactante e expropriador, mas se ignora que ele consome bens feitos sob o modo de produção capitalista e que asseguram a reprodução do circuito econômico de reprodução ampliada do capital.

Em uma sociedade de mercado capitalista as necessidades humanas apenas são relevantes se aparecerem como demanda monetária no mercado. É óbvio que em uma sociedade capitalista as necessidades transformam-se em poder aquisitivo monetário, se não fosse assim não seriam reconhecidas. Porque o dinheiro constitui, como disse Marx sarcasticamente, a real e verdadeira comunidade. O dinheiro é quem serve como elo nas relações sociais e concomitantemente na relação da sociedade com a natureza (Altvater, 2006, p. 331-332).

Consequentemente, o componente ideológico de tal discurso 'substitutivo' na prática leva à troca de categorias decisivas para a definição do tipo de intervenção política e de prioridade estratégica nas lutas sociais (Bourdieu e Wacquant, 2004): as que antes eram vistas como fundamentais passam à condição de secundárias - ou até mesmo de historicamente superadas. Da ênfase em políticas públicas construídas sob institucionalidades públicas passa-se à execução de projetos via organizações não governamentais (ONGs) e empresas, por meio da chamada 'responsabilidade socioambiental'. Da explicitação dos conflitos como condição para a democratização passa-se à lógica do consenso e do diálogo, como se a desigualdade e o antagonismo de interesses de classe tivessem acabado ou como se a comunicação entre agentes sociais levasse ao consenso e à emancipação.

Ao contrário dessa linha argumentativa culturalista ou fundada na linguagem e na conciliação de classe (ou no fim da mesma), reafirmamos que, na sociedade contemporânea globalizada, há uma expansão contínua do mercado de matéria-prima, para suprir a demanda por mercadorias, acompanhada da precarização do trabalho, buscando assegurar a margem de lucro necessária à acumulação e à reprodução ampliada do capital. Assim, os Estados e as multinacionais recorrem sucessivamente à extração de minérios, água e energia de regiões antes à margem da industrialização em um novo momento do processo de acumulação primitiva definido por Marx, que teve na expropriação da terra camponesa um momento fundamental. Esse processo atual foi denominado por Harvey (2004) como 'acumulação por espoliação', uma vez que a expressão 'primitiva' remetia a uma ideia de 'original', e não de continuidade, como parece mais adequado a Harvey. Essa expansão capitalista, porém, é limitada pela natureza mediatizada pelas relações de produção fundadas na expropriação e apropriação privada. 
O movimento de remoção desses limites pelo capital é acompanhado, portanto, de crises e da ação política de movimentos sociais antissistêmicos, que acabam por interromper a reificação das relações sociais, abrindo espaço para a reflexão sobre as raízes do problema e sobre as possíveis alternativas societárias existentes. Assim, mais do que nunca, o trabalho e as classes se evidenciam como categorias determinantes para o entendimento da sociedade e a atuação superadora das relações sociais capitalistas.

É inegável que a afirmação das diferenças é uma exigência contemporânea para a construção de outro patamar societário. Porém, para a tradição crítica, esse movimento vem no mesmo âmbito da luta pela igualdade, posto que não são movimentos antagônicos; ao contrário, são complementares na emancipação. A diferença se define nas relações sociais de poder, econômicas e institucionais. Portanto, no capitalismo, essas relações se formam em um mesmo contexto em que há processos de discriminação e desigualdade que não podem ser confundidos com o respeito ao diferente. Desigual não é sinônimo de plural. O antagônico de desigual é igual; e de diferente é a indiferença ou a homogeneização econômica e cultural. A livre manifestação de cada um se vincula à superação das condições materiais de expropriação e dominação que historicamente se configuraram.

Isso não significa dizer que com um hipotético fim do capitalismo os problemas ambientais estarão imediatamente resolvidos. Problemas são questões que nos colocamos diante de certas condições, relações, apropriações e usos, e se vinculam à capacidade linguística de significar, representar, fazer juízo de valor (senso ético). Assim, desde que formamos as primeiras comunidades, fazemos questionamentos sobre o sentido de nossa existência, sobre o que somos e o que fazemos, se isso é bom ou ruim etc., e isso permanecerá em qualquer sociedade. O que se pode afirmar é que os problemas ambientais, foco do presente ensaio, configuram-se no capitalismo em determinadas formas que não equivalem ao que foi anteriormente e nem ao que virá. E essas formas precisam ser enfrentadas concretamente, e não como fatores descolados das relações complexas e materiais que as constituem.

Essa linha argumentativa da ecologia política crítica e marxista é importante para as ações em educação ambiental, pois evita que caiamos na armadilha do discurso abstrato que coloca na espécie humana uma ruindade ou uma bondade inerente, ou que culpabiliza os comportamentos individuais, como se os indivíduos interagissem com o planeta sem mediações sociais, sem ser parte de uma sociedade, que é também produzida por esses indivíduos.

(...) a unidade (o identitário) e a diversidade (o diferente), apesar de contraditórias, são concebidas corretamente em sua unidade. (...) Numa visão dialética, os dois conceitos superam-se na particularidade (em nossa análise, a particularidade do 
sujeito). Entretanto, para a visão pós-moderna a diferença é apenas fundante e não se desenvolve em direção à particularidade do sujeito que é construída na interface do identitário com o diferente. O reconhecimento do diferente do outro é feito na perspectiva de firmar minha diferença para com aquele. A diferença encerra-se sobre si mesma sem intersubjetividade, portanto, em ruptura com o gênero humano. Daí que o outro não seja de fato aceito como diferente, mas simplesmente reconhecido como diferente, na medida em que funda a minha diferença. Assume, portanto, um papel estático e paralisador conduzindo ao narcisismo, ao individualismo e à fragmentação - um termo "em si" desgarrado de contraditórios. Na perspectiva oposta, a diferença é componente dialético do identitário, o qual é incluído como parte da definição da particularidade, junto com a diferença. Na realidade, não há como definir o identitário sem o diferente nem o diferente sem o identitário. Ou seja, o indivíduo é produto dessa dialética que resulta na sua particularidade. O que reivindica para o indivíduo não é a pura diferença (que fragmenta), mas a sua particularidade (que une, porque expressa a sua diferença no identitário, na genericidade) (Freitas, 2005, p. 79).

\section{Os movimentos sociais e as lutas ambientais}

Por sua origem nas classes médias europeias e norte-americanas, o movimento ambientalista é identificado, de forma mais imediata, com as forças sociais que se configuraram nesta fase de reorganização do capitalismo e suas 'bandeiras': defesa dos valores 'ecologicamente adequados'; da diversidade de expressões e cultural; da tolerância; do zelo com o planeta (Loureiro, 2006). Tal cenário propicia, portanto, que os chamados novos movimentos sociais, voltados para os valores ditos pós-materialistas e para a afirmação cultural, com forte ênfase nas subjetividades e nas diferenças, assumam o 'ambiental' como algo inerente às suas finalidades, enquanto os movimentos sociais, voltados para a emancipação, a política e a tomada e superação do Estado, visando à construção de outra sociedade, diante de suas históricas lutas sociais, só o fizeram posteriormente. No entanto, para a perspectiva crítica da ecologia política, existem pelo menos três fatores que evidenciam por que os movimentos sociais não podem ser pensados como secundários para esse debate.

Primeiro, porque, independentemente de utilizarem categorias ambientalistas, suas lutas e projetos políticos se referem à reestruturação da sociedade, e qualquer movimento nesse sentido representa novas formas de se relacionar com a natureza (sejam elas mais ou menos sustentáveis) - portanto, algo de relevante interesse para qualquer um que tenha no ambiente uma preocupação, questão ou desafio. Desconsiderar as lutas dos movimentos sociais vistos como clássicos, que denunciam as mazelas do capitalismo, 
é um grave equívoco que despolitiza o debate e estabelece uma leitura evolucionista da sociedade, pouco compatível com a dinâmica contraditória do real e com as necessidades materiais que perduram para a maioria absoluta das pessoas.

Segundo, porque, principalmente na última década, as lutas dos movimentos sociais na América Latina se destacaram por terem enfrentado e exposto as incongruências de processos produtivos envoltos com o agronegócio, a indústria de celulose, a mineração, a pecuária extensiva e a privatização da água. Sem dúvida, isso deu materialidade ao debate ambiental e o trouxe para a arena política e para o mundo econômico como antes não se tinha alcançado. Como bem coloca Mészáros (19889 e 2002), a valorização do capital torna indissociável a violência social da violência ambiental. Ou seja, condições objetivas propiciaram que o 'ambiental' fosse incorporado pelos movimentos sociais como elemento estratégico nas lutas populares e democráticas e para a explicitação dos conflitos ambientais, uma vez que a disputa por bens naturais e seu controle na apropriação e uso é inerente à propriedade privada capitalista.

Terceiro, porque o tema ecológico não é propriedade de nenhum agente social, nem mesmo dos que com ele se identificam e por ele lutam de forma mais direta. É, portanto, categoria estratégica da prática política e fator de identidade entre sujeitos e grupos. Nesse sentido, concordamos plenamente com Alier quando afirma:

(...) a história está repleta de movimentos ecológicos dos pobres, ou seja, de conflitos sociais com conteúdo ecológico cujos atores tinham uma percepção ecológica. A palavra 'ecologia' não se refere aos luxos estéticos da vida, mas ao fluxo de energia e materiais, à diversidade biológica e ao uso agroecológico do solo e, portanto, resulta absurdo pensar que a consciência ecológica é uma novidade nascida nos círculos ricos dos países ricos (1998, p. 31).

A não utilização da categoria 'ambiente' como estratégia de luta política dos movimentos sociais até pelo menos a década de 1990 tem duas explicações no caso brasileiro. O modo como o ambientalismo se consolidou durante os anos de 1970 e 1980 fez que ele assumisse muito do debate europeu. Além disso, por ser um pensamento de classe média e pertencendo à elite intelectual, veio com a desvantagem de não conseguir obter a adesão de grupos populares, uma vez que emerge ainda em um momento do fim da ditadura militar e da redemocratização do país, e essa era a questão prioritária para os grupos de maior poder econômico. Com isso, um perfil majoritariamente fundado em abordagens estruturadas na cisão cultura-natureza ou em uma leitura idealizada da natureza impedia o diálogo com os movimentos sociais. 
O outro elemento se relaciona ao fato de que não só os movimentos sociais se rearticulam tardiamente (nos anos de 1980), como também as suas formas de organização se voltaram com muita ênfase (e não sem motivos) para o enfrentamento da ditadura. Assim, o foco se localizava na superação dos intensos mecanismos de dominação e no fortalecimento da democracia no país (Fontes, 2006).

Todavia, para além desses motivos históricos de afastamento, é fato também que há crescente reflexão sobre o caráter inovador ou não dos novos movimentos sociais, incluindo aí o ambientalismo, e se há rupturas ou não desses com os movimentos sociais.

Os novos movimentos sociais, quando 'descolam' a luta pela afirmação da diferença e do plural das demais questões estruturais, acabam provocando um esvaziamento do debate político que favorece a ação fragmentada e focada na esfera do consumo e do indivíduo. Assim, mesmo que se evidenciem aparentemente como algo novo, ao se analisarem a dinâmica e as contradições sociais concretas, verifica-se que não raramente tais movimentos acabam por reproduzir os elementos fundamentais do atual estágio do capitalismo (Harvey, 2005).

Sem desconsiderar esse aspecto, para uma parte dos pesquisadores sobre o tema não há nada de substantivo que configure obrigatoriamente uma polarização entre movimentos sociais e novos movimentos sociais. Tais autores entendem que o que há de inovador/transformador na ação dos agentes sociais contemporâneos é um prolongamento dos movimentos sociais (o que eliminaria a necessidade do 'novo'), uma complexificação da luta política, procurando-se promover simultaneamente os valores igualdade e diversidade e não apenas um destes (Houtart, 2006).

Concordamos com essa perspectiva quando os chamados novos movimentos sociais não perdem a dimensão de classe nas suas análises. Reconhecer que algo é determinante não significa estabelecer uma hierarquia entre o que é mais ou menos importante. Algo determinante é algo tendencialmente relevante ou algo sem o qual não se entende o conjunto das relações sociais em um contexto ou as causas de um fato (Lukács, 2010). Logo, o determinante era e continua sendo o modo de produção capitalista, que estabelece como prioridade a acumulação de riquezas e não a satisfação de necessidades vitais.

A questão de classe é fundante do capitalismo, logo, central para qualquer movimento de ruptura e superação societária. Contudo, a violência contra a mulher, a dominação de gênero ou étnica, os preconceitos relativos à sexualidade ou qualquer outra manifestação ou opção na vida não são menos importantes para quem os vivenciam, qualificando a própria classe e conformando as relações sociais (Montaño e Duriguetto, 2011). Classe, na mesma linha de raciocínio de Thompson (2002), é estrutura e processo, conjunto de práticas culturais e políticas dotadas de historicidade e vin- 
culadas a relações e modos de produção.

Então, como articular as diferentes lutas sociais na luta de classes, contemplando as questões ambientais?

\section{Justiça ambiental}

A categoria 'conflito ambiental' para a estratégia política dos movimentos sociais ganha destaque na resposta a essa questão (Foster, 2002). Essa categoria qualifica e integra a ação organizada em defesa de justiça social e do direito à vida emancipada, saudável e sustentável, uma vez que trata das relações estabelecidas nos processos antagônicos de interesses entre agentes que disputam recursos naturais e buscam legitimar seus modos de vida. Como nos diz Foladori:

A análise da crise ambiental contemporânea deve partir das próprias contradições no interior da sociedade humana, contradições que não são biológicas, mas sociais, que não se baseiam na evolução genética, mas na história econômica, que não têm raízes nas contradições ecológicas em geral, mas naquelas que se estabelecem entre classes e setores sociais em particular (Foladori, 2001, p. 45).

Para o movimento de justiça ambiental, uma situação de injustiça ambiental caracteriza-se quando na sociedade se destina a maior carga dos danos ambientais a grupos sociais de trabalhadores ou grupos étnicos discriminados, entre outros segmentos em estado de maior vulnerabilidade social e econômica, ameaçando a integridade da saúde ambiental e comprometendo a sua reprodução social.

Essa condição, reveladora dos mecanismos de desigualdade socioambiental, estabelece-se em sociedades desiguais por meio de mecanismos políticos, sociais e econômicos que concentram os processos decisórios e privatizam os bens públicos, tornando possível e legítimo a utilização dos bens coletivos e naturais para interesses privados. Essa distribuição desigual por classe é entendida como intrínseca às economias capitalistas e necessária à reprodução ampliada do capital. Assim, na sociedade capitalista o acúmulo material das classes dominantes se dá mediado pela expropriação ambiental dos trabalhadores, e as taxas de lucro das grandes corporações empresariais se vinculam à degradação ambiental dos espaços de vida e de trabalho desses grupos e classes expropriadas (Gould, 2004).

Por outra parte, justiça ambiental pode ser entendida como um conjunto de práticas organizadas de agentes sociais que se encontram na condição de expropriados e que defendem politicamente projetos societários anticapitalistas, estando pautadas por princípios como: 
- equidade na distribuição das consequências ambientais negativas, de forma que nenhum grupo social, étnico ou de classe suporte uma parcela desproporcional dessas consequências;

- justo acesso aos bens ambientais do país;

- amplo acesso às informações relevantes sobre as atividades poluentes, tais como o uso dos recursos naturais, o descarte de seus rejeitos e a localização das fontes de risco;

- fortalecimento e favorecimento da constituição de sujeitos coletivos de direitos, isto é, de movimentos sociais e organizações populares capazes de interferirem no processo de decisão da política e da economia.

Ocorre que o movimento por justiça ambiental se caracteriza em oposição à corrente conservadora do pensamento ambientalista da 'modernização ecológica', atualmente hegemônica e que concebe: a) a natureza como composta apenas por recursos naturais (destituída de componentes socioculturais); b) a existência de problemas ambientais (e não de conflitos socioambientais); c) o enfrentamento de tais 'problemas' por meio de medidas administrativas e tecnológicas (e não por meio de processos políticos), uma vez que se considera tratar de desperdício ou escassez de recursos ambientais (e não do acesso e uso desigual dos bens ambientais). A modernização ecológica compreende ainda que a crise ambiental seja democrática, isso é, a humanidade como um todo, indistintamente, estaria igualmente sujeita aos efeitos nocivos da degradação ambiental planetária, independentemente de qualquer tipo de recorte social. Todos os humanos seriam igualmente responsáveis e vítimas da crise ambiental contemporânea (Acselrad, Mello e Bezerra, 2008).

\section{A educação ambiental crítica}

A educação ambiental crítica, é aquela que em síntese busca pelo menos três situações pedagógicas: a) efetuar uma consistente análise da conjuntura complexa da realidade a fim de ter os fundamentos necessários para questionar os condicionantes sociais historicamente produzidos que implicam a reprodução social e geram a desigualdade e os conflitos ambientais; b) trabalhar a autonomia e a liberdade dos agentes sociais ante as relações de expropriação, opressão e dominação próprias da modernidade capitalista; c) implantar a transformação mais radical possível do padrão societário dominante, no qual se definem a situação de degradação intensiva da natureza e. em seu interior, da condição humana.

Sua origem remete a meados da década de 1980 e início dos anos 1990, com o processo de redemocratização da sociedade brasileira, o que favoreceu a retomada de movimentos sociais de cunho emancipatório e o fortale- 
cimento de perspectivas críticas na educação e da educação popular. Diante desses fatos e da conjuntura favorável a um maior diálogo entre movimentos sociais, sindicatos de trabalhadores da educação, educadores em geral e ambientalistas, por força dos vínculos objetivos entre democratização do país, formação socioeconômica e degradação ambiental, a educação ambiental passou a ser vista como um processo contínuo de aprendizagem em que indivíduos e grupos tomam consciência do ambiente por meio da produção e transmissão de conhecimentos, valores, habilidades e atitudes.

Nessa mesma época, um elemento a mais, e de caráter decisivo, marcou a sua identidade: a forte inserção dos que atuavam na educação popular e adotavam a pedagogia crítica e libertadora de Paulo Freire. A educação ambiental no Brasil se volta, assim, para a formação humana, para a formação política. Objetivamente, isso significa dizer que o conceito central do ato educativo deixa de ser a transmissão de conhecimentos, como se isso per si fosse suficiente para gerar um 'sujeito ético' que se comportaria corretamente. É a própria práxis educativa, a indissociabilidade teoria-prática na atividade humana consciente de transformação do mundo e de autotransformação que ganha a devida centralidade. Isso implica favorecer a contínua reflexão das condições de vida, na prática concreta, como parte inerente do processo social e como elemento indispensável para a promoção de novas atitudes e relações que estruturam a sociedade.

Logo, ao se dar destaque à práxis educativa, crítica e dialógica, é preciso estruturar processos participativos que favoreçam a superação das relações de poder consolidadas e garantir o exercício da cidadania, principalmente daqueles que se encontram em situação de maior vulnerabilidade socioambiental (Loureiro, Azaziel e Franca, 2007). E isso significa dizer que não só a participação é fundamental, mas que a participação popular é determinante, posto ser a construção de processos em que os grupos expropriados e discriminados adquiram centralidade a condição para que as contradições e os conflitos da sociedade sejam explicitados, enfrentados e superados pelo protagonismo daqueles que portam materialmente o que é distinto do poder hegemônico - portanto, a alternativa possível concretamente.

Cumpre destacar que o cenário atual do campo da educação ambiental compreende três macrotendências, as quais, por sua vez, agregam em seu interior diversas correntes político-pedagógicas que representam diferentes abordagens teóricas e práticas dessa prática educativa (Layrargues e Lima, 2011): a conservacionista, a pragmática e a crítica.

A primeira macrotendência, a conservacionista, é expressão tendencial do início do processo histórico de constituição do campo. Relaciona-se com práticas educativas que proporcionam um contato íntimo com a natureza, mas estão distanciadas das dinâmicas sociais e políticas, e de seus respectivos conflitos de poder. Apoia-se nos princípios da ecologia, na valorização 
da dimensão afetiva em relação à natureza e na mudança dos comportamentos individuais em relação ao ambiente, mudança baseada na constatação da necessidade de uma mudança cultural civilizatória que relativize o antropocentrismo como paradigma dominante. É uma tendência histórica, conceitualmente forte e bem consolidada entre seus expoentes, mas que não parece ser a tendência hegemônica na atualidade. Encontra-se 'renovada' hoje pelas temáticas que vinculam a educação ambiental à 'pauta verde' do ambientalismo - como biodiversidade, ecoturismo, unidades de conservação e determinados biomas específicos -, a exemplo da vinculação temática da educação ambiental com os manguezais, com o cerrado, com os ecossistemas costeiros etc.

A segunda macrotendência, a pragmática, abrange especialmente as correntes da educação para o desenvolvimento sustentável, da educação para o consumo sustentável, e da educação ambiental no âmbito dos resíduos sólidos e no âmbito das mudanças climáticas. É expressão do ambientalismo de resultados, do pragmatismo contemporâneo e do ecologismo de mercado que decorrem da hegemonia neoliberal instituída no contexto brasileiro desde os anos 1990. Essa macrotendência tem suas raízes no estilo de produção e consumo advindos do pós-guerra, e poderia apresentar uma leitura crítica da realidade caso aproveitasse o potencial crítico da articulação das dimensões sociais, culturais, econômicas, políticas e ecológicas na reflexão sobre o padrão do lixo gerado pelo atual modelo desenvolvimentista. Porém, sua trajetória apontou ideologicamente para um viés pragmático (Layrargues, 2002), servindo apenas como um mecanismo de compensação para corrigir a 'imperfeição' do sistema produtivo baseado no consumismo, na obsolescência planejada e nos descartáveis. Isso porque esse sistema proporciona um significativo aumento na geração do lixo, o qual necessariamente deve ser reciclado no metabolismo industrial para manter a viabilidade do modelo de acumulação do capital. Dessa forma, essa vertente, que responde à 'pauta marrom' do ambientalismo, por ser essencialmente urbano-industrial, converge com o consumo sustentável e também se relaciona com a economia de energia ou água, o mercado de carbono, as ecotecnologias legitimadas pelo rótulo verde, a diminuição da 'pegada ecológica' e todas as expressões do conservadorismo dinâmico que promovem mudanças superficiais, tecnológicas e comportamentais. Essa perspectiva percebe o meio ambiente pela ótica da modernização ecológica, ou seja, destituído de componentes humanos, como uma mera coleção de recursos naturais em processo de esgotamento, aludindo-se então ao combate ao desperdício e à revisão do paradigma do lixo que passa a ser concebido como resíduo, ou seja, que pode ser reinserido no metabolismo industrial. Deixa à margem das considerações a questão da distribuição desigual dos custos e benefícios da apropriação dos bens ambientais pelos processos desenvolvi- 
mentistas e resulta na promoção de reformas setoriais na sociedade sem questionar seus fundamentos de base, inclusive aqueles responsáveis pela própria crise ambiental. A macrotendência pragmática representa, nesse sentido, uma forma de ajustamento ao contexto neoliberal de redução do Estado à sua dimensão mínima que afeta o conjunto das políticas públicas e sociais, entre as quais figuram as políticas ambientais. Essa educação ambiental será a expressão do mercado, na medida em que ela apela ao bom-senso dos indivíduos para que sacrifiquem um pouco do seu padrão de conforto e convoca a responsabilidade das empresas para que renunciem a uma fração de seus benefícios em nome da governabilidade geral.

Ambas essas macrotendências são expressões conservadoras da educação ambiental, uma vez que não questionam a estrutura social vigente, propondo apenas reformas setoriais. Apontam, sobretudo, para mudanças culturais ou institucionais reconhecidamente relevantes, mas que dificilmente podem ser concretizadas sem que também se transformem as bases econômicas e políticas da sociedade. Resultam em ações individuais e comportamentais no âmbito doméstico e privado, de forma a-histórica, apolítica, conteudística, instrumental e normativa. Ao adotarem uma perspectiva estritamente ecológica da questão ambiental, perdem de vista as dimensões sociais, políticas e ideológicas indissociáveis de sua gênese e dinâmica, porque não incorporam as posições de classe e as diferentes responsabilidades dos atores sociais enredados na crise ambiental; porque reduzem a complexidade do fenômeno ambiental a uma mera questão de inovação tecnológica; e porque, finalmente, creem que os princípios do mercado são capazes de promover a transição no sentido da sustentabilidade. Assim, não superam o paradigma hegemônico que tende a tratar o ser humano como um ente genérico e abstrato, reduzindo os humanos à condição de causadores e vítimas da crise ambiental, desconsiderando qualquer recorte social.

As macrotendências conservacionista e pragmática representam duas tendências e dois momentos de uma mesma linhagem de pensamento que se foi ajustando aos movimentos político-econômicos até adquirir a face 'modernizada' que hoje a caracteriza. Pode-se dizer que a macrotendência pragmática representa uma derivação histórica da conservacionista, na medida em que é fruto do processo de adaptação ao novo contexto social, econômico e tecnológico.

Para a macrotendência crítica, não basta lutar por uma nova cultura na relação entre o ser humano e a natureza; é preciso lutar ao mesmo tempo por uma nova sociedade. Não se trata de promover apenas reformas setoriais, mas uma renovação multidimensional capaz de transformar o conhecimento, as instituições, as relações sociais e políticas, e os valores culturais e éticos. Trata-se de incluir no debate ambiental a compreensão político-ideológica dos mecanismos da reprodução social e o entendimento de que a relação 
entre o ser humano e a natureza é mediada por relações socioculturais e classes historicamente construídas. Essa tendência traz então uma abordagem pedagógica que problematiza os contextos societários em sua interface com a natureza. Por essa perspectiva, definitivamente não é possível conceber os problemas ambientais dissociados dos conflitos sociais; afinal, a crise ambiental não expressa problemas da natureza, mas problemas que se manifestavam na natureza. A causa constituinte da questão ambiental tem origem nas relações sociais, nos modelos de sociedade e de desenvolvimento prevalecentes.

\section{Considerações finais}

Nos movimentos de educação ambiental crítica, justiça ambiental e ecologia política ocorre um processo argumentativo contínuo de ressignificação ideológica da questão ambiental, agindo como contraponto das interpretações hegemônicas do senso comum acerca do fenômeno socioambiental. Todos possuem elementos em comum que conformam o amálgama mediante o qual se pode efetuar a crítica e operar politicamente a favor da transformação social. Na disputa por outra interpretação da questão ambiental, enfatizam que a categoria 'ambiente' não é composta apenas de conteúdos ecológico/ambientais, mas também de conteúdos sociais e culturais específicos, diferenciados e muitas vezes contraditórios; condenam a lógica dos interesses promovida pela razão utilitária do mercado e elogiam a lógica dos direitos, especialmente quando se trata de sociedades fortemente desiguais; revelam que, para além dos 'problemas ambientais', existem 'conflitos socioambientais', e que a categoria 'trabalho' é central para a reflexão ter solidez no entendimento do fenômeno.

Procuramos apresentar o quadro em que se situam a educação ambiental crítica, a justiça ambiental e a ecologia política, e, nesse contexto, constata-se que, afinal de contas, elas representam, em seus campos particulares, oportunidades de enfrentamento contra-hegemônico da realidade socioambiental. Mais do que isso, representam possibilidades de luta política por outro modelo societário, na medida em que suas vertentes críticas se alinham numa possível e desejável aliança teórica, garantindo que, do ponto de vista da questão ambiental, as condições de superação das contradições do capitalismo estejam estrategicamente na direção do realizável. 


\section{Notas}

1 Professor associado da Faculdade de Educação da Universidade Federal do Rio de Janeiro (UFRJ), Rio de Janeiro, Brasil. Doutor em Serviço Social pela Universidade Federal do Rio de Janeiro (UFRJ). <floureiro@openlink.com.br> Correspondência: Universidade Federal do Rio de Janeiro, Faculdade de Educação, Avenida Pasteur, 250F, Praia Vermelha, Rio de Janeiro, Rio de Janeiro, Brasil, CEP 22290-240.

2 Professor adjunto da Faculdade UnB Planaltina (FUP), da Universidade de Brasília (UnB), Planaltina, Brasília, Distrito Federal. Doutor em Ciências Sociais pela Universidade Estadual de Campinas (Unicamp). <philippe.layrargues@gmail.com>

\section{Referências}

ACSELRAD, Henri; MELLO, Cecília C. do A.; BEZERRA, Gustavo das N. O que é justiça ambiental. São Paulo: Garamond, 2008.

ALIER, J. M. Da economia ecológica ao ecologismo popular. 3. ed. Blumenau: Furb, 1998.

O ecologismo dos pobres: conflitos ambientais e linguagens de valoração. São Paulo: Contexto, 2007.

ALTVATER, E. O fim do capitalismo como o conhecemos: uma crítica radical do capitalismo. Rio de Janeiro: Civilização Brasileira, 2010.

Existe un marxismo ecológico? In: BORÓN, Atilio; AMADEO, J.; GONZÁLEZ, S. (Orgs.). La teoría marxista hoy: problemas y perspectivas. Buenos Aires: Clacso, 2006. p. 341-364.

BOURDIEU, Pierre. A economia das trocas simbólicas. 6. ed. São Paulo: Perspectiva, 2005.

O poder simbólico. Rio de Janeiro: Bertrand Brasil, 2007.

BOURDIEU, Pierre; WACQUANT, Loïc. O imperialismo da razão neoliberal. Possibilidades, Anápolis, v. 1, n. 1, p. 24-28, jul.-set. 2004.
FOLADORI, Guillermo. Limites do desenvolvimento sustentável. Campinas: Editora da Unicamp, 2001.

FONTES, Virgínia. Sociedade civil no Brasil contemporâneo: lutas sociais e luta teórica na década de 1980. In: LIMA, Júlio César França; NEVES, Lúcia Maria Wanderley (Orgs.). Fundamentos da educação escolar do Brasil contemporâneo. Rio de Janeiro: Editora Fiocruz, 2006. p. 73-117.

FOSTER, J. B. Ecology against capitalism. Nova York: Monthly Review Press, 2002.

FREITAS, L. C. de. Uma pós-modernidade de libertação: reconstruindo esperanças. Campinas: Autores Associados, 2005.

GORZ, André. Ecologia e politica. Lisboa: Notícias, 1976.

GOULD, K. A. Classe social, justiça ambiental e conflito político. In: ACSELRAD, Henri; HERCULANO, Selene; PÁDUA, José A. (Orgs.). Justiça ambiental e cidadania. Rio de Janeiro: Relume Dumará-Fundação Ford, 2004. p. 69-80.

HARVEY, D. Espaços de esperança. São Paulo: Loyola, 2005. 
. O novo imperialismo. São Paulo: Loyola, 2004.

HONNET, A. Luta por reconhecimento. São Paulo: Editora 34, 2003.

HOUTART, F. Los movimientos sociales y la construcción de un nuevo sujeto histórico. In: BORÓN, Atilio; AMADEO, Javier; GONZÁLEZ, Sabrina (Orgs.). La teoría marxista hoy: problemas y perspectivas. Buenos Aires: Clacso, 2006. p. 435-444.

LAYRARGUES, Philippe Pomier. O cinismo da reciclagem: o significado ideológico da reciclagem da lata de alumínio e suas implicações para a educação ambiental. In: LOUREIRO, Carlos Frederico B.; LAYRARGUES, Philippe Pomier; CASTRO, Ronal de Souza (Orgs.). Educação ambiental: repensando o espaço da cidadania. São Paulo: Cortez, 2002. p. 179-219.

Identidades da educação ambiental: descobrimos que somos diferentes. Saberemos conviver com isso? In: DIB-FERREIRA, Declev Reynier; GUERREIRO, Jacqueline (Orgs.). VI Fórum Brasileiro de Educação Ambiental: participação, cidadania e educação ambiental. Niterói: Instituto Baía de Guanabara. 2010. p. 34-38.

LAYRARGUES, Philippe Pomier; LIMA, Gustavo F. da C. Mapeando as macrotendências político-pedagógicas da educação ambiental contemporânea no Brasil. In: ENCONTRO PESQUISA EM EDUCAÇÃO AMBIENTAL, 6. Anais... Ribeirão Preto: Universidade de São Paulo - Campus Ribeirão Preto, 2011.

LIMA, G. F. da C. Educação ambiental: formação, identidades e desafios. Campinas: Papirus, 2011.

. Formação e dinâmica do campo da educação ambiental no Brasil: emergências, identidades e desafios. 2005. Tese (Doutorado em Ciências Sociais) - Instituto de Filosofia e Ciências Humanas Universidade de Campinas, Campinas, 2005.
LOUREIRO, Carlos Frederico B. (Org.). A questão ambiental no pensamento crítico: natureza, trabalho e educação. Rio de Janeiro: Quartet, 2007.

. Educação ambiental e 'teorias críticas'. In: GUIMARÃES, M. (Org.). Caminhos da educação ambiental: da forma à ação. 3. ed. Campinas: Papirus, 2008. p. 51-86.

O movimento ambientalista e o pensamento crítico: uma abordagem política. 2. ed. Rio de Janeiro: Quartet, 2006.

; AZAZIEL, M.; FRANCA, N. Educação ambiental e conselho em unidades de conservação: aspectos teóricos e metodológicos. Rio de Janeiro: Ibase, 2007.

LUKÁCS, György. Prolegômenos - para uma ontologia do ser social. São Paulo: Boitempo, 2010 .

MÉSZÁROS, István. O desafio e o fardo do tempo histórico. São Paulo: Boitempo, 2008.

Para além do capital. São Paulo: Boitempo, 2002.

Produção destrutiva e Estado capitalista. São Paulo: Ensaio, 1989.

MONTAÑO, C.; DURIGUETTO, M. L. Estado, classe e movimentos sociais. São Paulo: Cortez, 2011.

MORIN, Edgar. O método 1: a natureza da natureza. 2. ed. Porto Alegre: Sulina, 2003.

MOUFFE, C. Identidade democrática e política pluralista. In: MENDES, C. (Org.). Pluralismo cultural, identidade e globalização. Rio de Janeiro: Record, 2001. p. 327-374.

ORGANISTA, J. H. O debate sobre a centralidade do trabalho. São Paulo: Expressão Popular, 2006.

RIOS, Natália Tavares. Educação ambiental em escolas próximas ao pólo industrial de Campos Elíseos: a influência do contexto 
industrial e do risco. 2011. Dissertação (Mestrado em Educação) - Programa de Pós-graduação em Educação, Universidade Federal do Rio de Janeiro, Rio de Janeiro, 2011.

THOMPSON, Edward P. A formação da classe operária inglesa. Rio de Janeiro: Paz e Terra, 2002. $3 \mathrm{v}$.

Recebido em 24/10/2011

Aprovado em 04/08/2012 